\title{
ENVELHECER COM SENTIDO: REFLEXÃO À LUZ DA FENOMENOLOGIA EXISTENCIAL
}

Márcia Marrocos Aristides Barbiero; Universidade Federal do Paraná; marciamarrocos@gmail.com; Conceição da Silva Brito; Universidade Federal do Paraná; enfbryto@gmail.com Patrícia Rosa Gonçalves Leta; Universidade Federal do Paraná; patriciargl@hotmail.com; Fatima Denise Padilha Baran; Universidade Federal do Paraná; fatima_enfermagem@yahoo.com.br; Reuber Lima de Souza; Universidade Federal do Paraná; reuber_souza@hotmail.com; Aline de Sousa Falcão; Universidade Federal do Paraná; alinesousafalcão@hotmail.com; Susanne Elero Betiolli; Universidade Federal do Paraná; susanne.elero@yahoo.com.br; Maria Helena Lenardt; Universidade Federal do Paraná; curitiba.helena@gmail.com

\section{RESUMO}

Introdução: envelhecer é uma experiência singular e compreender a velhice faz parte dos mecanismos de enfrentamento e adaptação do processo de envelhecimento. É um período em que o indivíduo, em sua particularidade, não cessa a capacidade fundamental do ser humano de construir um sentido e atribuir significado às suas vivências. Objetivo: desenvolver uma reflexão acerca do sentido da vida no processo de envelhecimento e na velhice. Método: trata-se de um estudo de reflexão sobre o(a) envelhecimento/velhice fundamentado na fenomenologia existencial de Viktor Emil Frankl (1905-1997). Resultados: Os subsídios teóricos da fenomenologia existencial trazem melhor compreensão sobre o curso do envelhecimento e da velhice, da busca de identidade e autenticidade humanas frente à existência. A teoria da busca por um sentido proporciona ao indivíduo o enfretamento eficaz dos desafios no decorrer e nessa fase da vida. $O$ sentido da vida é força motivadora do ser humano, faz parte dos questionamentos existenciais, se modifica de acordo com a pessoa, suas experiências e momento vivenciado. A área gerontológica considerada também como uma prática social no cuidado à pessoa idosa deve fomentar, durante o envelhecimento e na velhice, as condições para o compartilhamento de experiências dos idosos. O compartilhar estimula a relação do "ser-no-mundo" e revela significações para melhor compreensão do cotidiano e da saúde dos idosos. Conclusão: A reflexão fenomenológica existencial viabiliza a promoção da integralidade do cuidado, auxilia no enfrentamento de situações adversas no envelhecimento e na velhice, potencializa os resultados positivos de saúde e a percepção do bem-estar dos idosos.

Palavras-chave: Envelhecimento; Idoso; Sentido da vida; Gerontologia.

Agradecimentos: À Coordenação de Aperfeiçoamento de Pessoal de Nível Superior (CAPES) pela bolsa no Programa de Pós-Graduação em Enfermagem. 